\title{
BMJ Open Changes in prescribing rates of sodium- containing medications in the UK from 2009 to 2018: a cross-sectional study with interrupted time series analysis
}

\author{
Chengsheng Ju (D) , ${ }^{1}$ Li Wei (D) , ${ }^{1}$ Isla S Mackenzie (D) ,, Thomas M MacDonald (D) , ${ }^{2}$ \\ Jacob George (D) ${ }^{2}$
}

To cite: Ju C, Wei L,

Mackenzie IS, et al. Changes in prescribing rates of sodiumcontaining medications in the UK from 2009 to 2018: a crosssectional study with interrupted time series analysis. BMJ Open 2021;11:e043566. doi:10.1136/ bmjopen-2020-043566

- Prepublication history and additional materials for this paper is available online. To view these files, please visit the journal online (http://dx.doi org/10.1136/bmjopen-2020043566).

Received 07 August 2020 Revised 23 January 2021 Accepted 30 January 2021

Check for updates

(c) Author(s) (or their employer(s)) 2021. Re-use permitted under CC BY-NC. No commercial re-use. See rights and permissions. Published by BMJ.

${ }^{1}$ Research Department of Practice and Policy, School of Pharmacy, University College London, London, UK

${ }^{2}$ Molecular and Clinical

Medicine, University of Dundee, Dundee, UK

Correspondence to

Professor Li Wei;

I.wei@ucl.ac.uk

\section{ABSTRACT}

Objective Effervescent, soluble, dispersible

formulations contain considerable amounts of sodium. In 2013, we previously confirmed the association between sodium-containing medications and cardiovascular risks. This study aimed to determine the changes in the prescribing pattern in clinical practice following this publication.

Design A longitudinal cross-sectional study. Setting Primary care in the UK from 2009 to 2018. Participants Prescribing information in The Health Improvement Network (THIN) and Prescription Cost Analysis (PCA) databases in the UK.

Outcome measurements Prescription rates per 10000 inhabitants were calculated using the number of prescriptions or the number of drug-using patients over the total number of inhabitants, and the prescription rates were measured at annual intervals. Prescribing trends from 2009 to 2018 were indexed with yearly data from THIN and PCA. Interrupted time series analysis (ITSA) was conducted with monthly data in THIN.

Results From the THIN database, a total of 3651419 prescription records from 446233 patients were included. The prescribing rate of sodium-containing medications changed from 848.3/10000 inhabitants in 2009 to $571.6 / 10000$ inhabitants in 2018. The corresponding figures from PCA data were of 631.0/10000 inhabitants in 2009 and 423.8/10 000 inhabitants in 2018. ITSA showed the prescribing trend reduced significantly during the postpublication period (prescribing rate: slope change $=-0.26 ; 95 \% \mathrm{Cl}-0.45$ to $-0.07 ; p=0.009$; proportion of patients: slope change $=-0.22 ; 95 \% \mathrm{Cl}-0.35$ to $-0.09 ; p<0.001$ ), but no change in postpublication level from baseline. The prescribing rates for the non-sodiumcontaining standard formulations were relatively stable over the study period. The reduction in the proportion of patients using sodium-containing medications was only significant in patients over 45 years old.

Conclusions The prescribing of sodium-containing medications in the UK primary care has declined significantly during the postpublication period. Changes in the prescribing trends for sodium-containing medications varied across regions of the UK and patient age groups.
Strengths and limitations of this study

- This was the first study examining changes in the prescribing of sodium-containing formulations in the UK.

- This study involved a large number of prescription records and patient records from two large databases in the UK.

- We did not investigate comorbidities associated with discontinuation of sodium-containing medications.

- The effects of potential other factors cannot be ruled out.

\section{INTRODUCTION}

There is little doubt that excess dietary salt is a major public health problem. High salt intake has been emphasised as a major cardiovascular risk factor. ${ }^{12}$ In 2010, it was estimated that 1.65 million cardiovascular deaths were attributed to high sodium salt consumption. ${ }^{3}$ The UK Food Standards Agency campaign was launched in 2004 to try to reduce salt intake in the estimated 26 million people in the UK who have high dietary salt. ${ }^{4}$ Reducing salt intake would very significantly reduce the multiple adverse effects on health ${ }^{5}$ such as hypertension, which leads to substantial economic benefits. ${ }^{6}$ While a very considerable effort is being made to reduce salt intake in the population in general, we are concerned that a significant sodium salt load is being ingested via certain medications. The recommended sodium intake for an adult is between 50 and $65 \mathrm{mmol} /$ day. However, dispersible paracetamol can contain up to $18.6 \mathrm{mmol}$ of sodium and effervescent preparations can contain up to $16.9 \mathrm{mmol}$ of sodium per $500 \mathrm{mg}$ tablet. Therefore, the maximum daily dose of $4000 \mathrm{mg} /$ day or eight tablets will result in ingestion of twice the recommended daily allowance of sodium in one medication alone. Despite this fact, the 
cardiovascular impact of these sodium-containing medications has long been neglected.

In November 2013, we published a UK database study in the BMJ on the association of sodium-containing effervescent medications on long-term cardiovascular risks. ${ }^{7} \mathrm{We}$ found that exposure to these medications was associated with a sevenfold increased risk of hypertension and a $16 \%$ higher risk for subsequent cardiovascular events. The results were later confirmed by a randomised, crossover trial evaluating the effect of effervescent paracetamol on blood pressure ${ }^{8}$ and a meta-analysis of eight studies. ${ }^{9}$ In 2015, the Pharmacovigilance Risk Assessment Committee of the European Medicines Agency (EMA) adopted the findings and have suggested labelling changes to these high sodium-containing medications. With regard to the use of sodium-containing medications, to date, there is only one recent French study that evaluated factors associated with exposure to effervescent drugs, ${ }^{10}$ while there is no updated information on prescribing patterns of sodium-containing medicines following the BMJ publication and EMA guideline changes. Given the detrimental health effects of excess sodium consumption by intake of the high sodium-containing medications, it is therefore important to evaluate the impact of the evidence change on the real-world practice of sodium-containing medication prescribing.

The aim of this study was to investigate prescribing patterns of effervescent, soluble and dispersible medications in the UK following the publication in November 2013 of discovery of an association with increased cardiovascular risk in patients prescribed these medications long term.

\section{METHODS}

\section{Study design and data source}

This was a longitudinal study using The Health Improvement Network (THIN) database and Prescription Cost Analysis (PCA) database for the period between 1 January 2009 and 31 December 2018, which were 5 years before and after the original 2013 publication.

THIN is a nationwide database of primary care records in the UK that contains around $6 \%$ of the total UK population. IQVIA Medical Research Data UK incorporating THIN, THIN is a registered trademark of Cegedim SA in the UK and other countries. Reference made to the THIN database is intended to be descriptive of the data asset licensed by IQVIA. This work uses de-identified data provided by patients as a part of their routine primary care. Previous studies have demonstrated the validity of THIN database for pharmacoepidemiological studies and its generalisability to the UK population. ${ }^{11} 12$ The PCA is a publicly published database containing yearly prescribing data for all prescriptions dispensed in the community by general practitioners, community pharmacists and appliance contractors. Separate PCA databases exist for the prescribing data in England, Scotland and Wales. The data were published by the National Health Service
(NHS) England, Public Health Scotland and NHS Wales, respectively. Prescriptions dispensed in hospitals or the private sector are not captured. Data in the PCA databases have been proven to reach a level of accuracy of 98\%-99\% and have been used for producing high quality research in pharmacoepidemiological studies from local research teams. ${ }^{1314}$

\section{Drug treatment}

In the original $2013 \mathrm{BMJ}$ publication, we previously identified 38 different preparations that are available on prescription as both effervescent or dispersible containing sodium and have had more than 1000 therapy events in Clinical Practice Research Datalink database. ${ }^{7}$ The same preparations were mapped in the PCA database and THIN database and were used as the study preparations in this follow-on study. Details of the preparations and classifications were included in online supplemental table S1 for the PCA database and online supplemental table $\mathrm{S} 2$ for the THIN database.

\section{Study outcome}

The primary outcome of this study was the prescribing trends of sodium-containing medications. Using the THIN data which contains patient-level data, we measured the prescribing trends by annual prescription rate per 10000 inhabitants, which were calculated as the number of sodium-containing medication prescriptions in a particular year divided by the corresponding yearly active population in THIN. We also measured the trends by yearly proportions of medication users per 10000 inhabitants, which were calculated as the number of patients who received a prescription of the study medications in a particular year divided by the corresponding yearly active population in THIN at each measurement. The number of active mid-year population in THIN was provided by the THIN database by summarising the demographic information for all patients included in the database. We excluded records of patients who received their first prescription of sodium-containing medication before the age of 18 years. We also examined the effect of demographic factors, that is, age and sex, on the prescribing of sodium-containing. We stratified the medication users according to sex (male or female) and age groups $(<45$ years, $45-54$ years, $55-64$ years, $65-74$ years, $75-85$ years or $\geq 85$ years).

To increase the robustness of our findings, we also indexed the prescribing trends by calculating the yearly prescription rates from the PCA database using the number of prescriptions divided by the estimated mid-year population of the same year for each region. Estimated mid-year population data was obtained from Office for National Statistics from 2009 to 2018 for England, Scotland and Wales on a yearly basis. In order to assess the regional variation in the impact of the 2013 publication, data in England, Scotland and Wales were analysed separately alongside the total data from these three regions. 


\section{Statistical analysis}

We first described long-term prescribing trends on the prescribing of sodium-containing medications from 2009 to 2018. We indexed the descriptive time series with yearly prescribing data from THIN and PCA databases, respectively. We also collated data on non-sodium-containing standard formulations, which are comparable to the study medications. The prescribing of sodium-containing medications was compared with that of the standard non-sodiumcontaining preparations.

To evaluate the impact of the publication on the prescribing of sodium-containing medications, we conducted the interrupted time series analysis (ITSA) using monthly prescribing data from the THIN database between 2012 and 2015. A shorter time frame was used for ITSA to avoid including effect of other intervention or evidence change during the study period. We used segmented linear regression models to examine changes in prescribing rates and proportions of sodium-containing medication users after the BMJ publication. The model both estimates the preintervention level and slope as well as controls the baseline level and slope of the time series to estimate the changes in level and slope after the intervention. The level change evaluates the immediate effect of the publication, and the slope change represents the gradual effect over time. The prescribing of standard non-sodium-containing formulations was used as the control series, and we repeated ITSA on the prescribing rates and proportion of patients to compare with the results of the sodium-containing medications. Autocorrelation of the times series was tested with Durbin-Watson statistic and corrected where appropriate. Seasonality was adjusted where appropriate. The intervention time was set as January 2014, with 2-month lag time from the publication in November 2013. There were 24 data points before and after the intervention. We analysed the prescribing of medications of each therapeutic class separately, where there were more than 100 observations at each measurement. We also analysed changes in the proportion of medication users in each sex and age group. A two-sided $\alpha$ of less than 0.05 was considered statistically significant. All analyses were conducted using SAS V.9.4 (SAS Institute).

\section{Sensitivity analyses}

We conducted two sensitivity analyses. First, we changed the time frame for the ITSA. We repeated the analysis with 30 months preintervention/postintervention, rather than 24 months. Second, we changed the intervention time to January 2016 and compared the prescribing trends 20142015 versus 2016-2017, when the EMA published the revision on the guidelines of excipient labelling, to assess the additive effects on prescribing rate.

\section{RESULTS}

\section{Prescribing trends from 2009 to 2018}

From the THIN database, we identified 3922400 prescription records of sodium-containing preparations from 579746 patients. Of these patients, 8620 patients with substandard records with data integrity issues defined by THIN were excluded. A total of 123893 patients who received their first prescription of the sodium-containing medication before the age of 18 years were further excluded. Finally, 3651419 prescription records from 446233 patients were included in the analyses.

The annual prescribing of sodium-containing medications reduced markedly from 2009 to 2018. The prescribing rate decreased from 848.3 prescriptions per 10000 inhabitants in 2009 to 792.5 prescriptions per 10000 inhabitants in 2013 (6.6\% reduction) and to 571.6 prescriptions per 10000 inhabitants in 2018 (27.9\% reduction). Most reductions occurred after 2013 (figure 1A). The trend for the prescribing of control drugs (non-sodium-containing standard formulations) was different. The prescribing rates increased from 7792.8 prescriptions per 10000 inhabitants in 2009 to 9018.0 prescriptions per 10000 inhabitants in 2013 (13.6\% increase). There was a plateau from 2013 to 2018, with a reading of 8954.6 prescriptions per 10000 inhabitants in 2018 (figure 1B). The same pattern was observed when the trend was measured in the proportion of medication users. There was a minor decrease from 249.3 patients per 10000 inhabitants in 2009 to 240.2 prescriptions per 10000 inhabitants in 2013 (3.7\%), and then reduced substantially to 169.9 patients per 10000 inhabitants in 2018 (29.3\%) (figure 1C). Similarly, when the trend for control formulations was measured in the proportion of patients, little change occurred from 2009 to 2018. The proportion of medication user was 1475.6, 1542.7 and 1417.3 patients per 10000 inhabitants in 2009, 2013 and 2018, respectively (figure 1D). The trends of prescribing measured by the proportion of patients stratified by sex were presented in figure $2 \mathrm{~A}$ and by age group in figure 2B.

We extracted 35069427 prescription records of sodium-containing medications, of which 29964749 were in England, 3488523 in Scotland and 1616155 in Wales. The trends derived from PCA data were similar to the trends from THIN data. The prescribing rate of sodium-containing medications changed from 631.0 prescription per 10000 inhabitants in 2009 to 612.1 prescription per 10000 inhabitants in 2013 (3.0\% reduction), and 423.8 prescription per 10000 inhabitants in 2018 (30.8\% reduction) (figure $3 \mathrm{~A})$. The measurements for non-sodium-containing formulations were 8759.7 in 2009, 10306.3 in 2013 and 9833.5 in 2018 (figure 3B). When stratified by regions, the results were presented in figure $3 \mathrm{C}$ for sodium-containing formulations and figure 3D for non-sodium-containing standard formulations. The trends in England and Scotland were similar to THIN data (England: 615.0 in 2009, 603.3 in 2013 and 413.6 in 2018; Scotland: 732.5 in 2009, 708.9 in 2013 and 501.5 in 2018), while in Wales, the prescribing decreased steadily over the period (623.4 in 2009 to 531.4 in 2013, and to 414.8 in 2018). For the control series of standard formulations, the trends were similar across all three regions. 


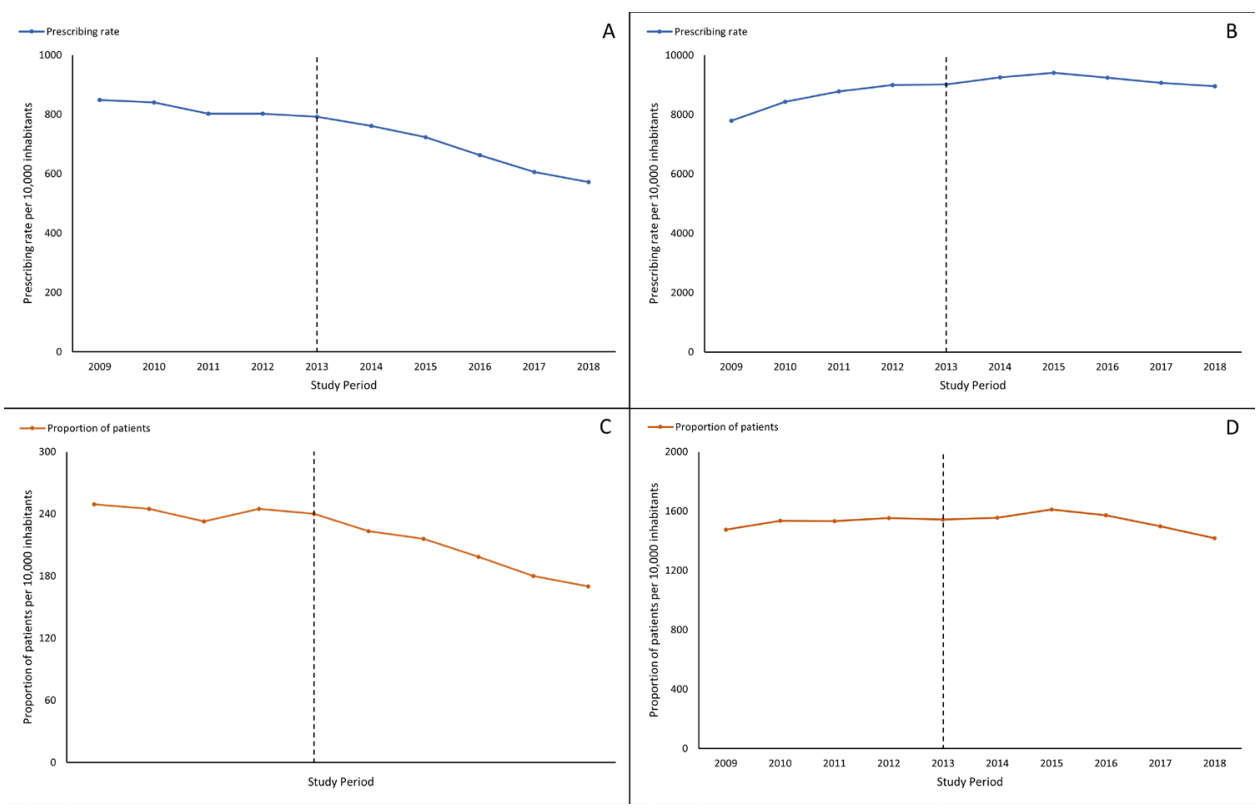

Figure 1 Prescribing trends of sodium-containing medications and control medications from 2009 to 2018 , The Health Improvement Network data; (A) sodium, prescribing rate; (B) control, prescribing rate; (C) sodium, proportion of patients; and (D) control, proportion of patients.

\section{ITSA of 2012-2013 versus 2014-2015: impact of the BMJ publication}

The monthly prescribing rate of sodium-containing formulations did not change during the 2-year period before the publication (baseline slope estimate $=0.03$; $95 \%$ CI -0.13 to 0.18 ). After the publication, the slope reduced significantly by 0.26 per month $(95 \%$ CI -0.45 to $-0.07 ; \mathrm{p}=0.009)$. No change in postpublication level was observed (level change $=0.59$; $95 \%$ CI -2.19 to 3.37; $\mathrm{p}=0.678$ ). While for the control series of the prescribing of non-sodium standard formulations, there was no change in either slope or level post publication (slope change $=1.14 ; 95 \%$ CI -0.99 to $3.27 ; \mathrm{p}=0.294$; level change $=22.3 ; 95 \%$ CI -8.14 to $52.7 ; \mathrm{p}=0.151$ ). When we stratify the prescriptions by the therapeutic classes, the significantly decreased slopes were observed for calcium supplements (slope change $=-0.03 ; 95 \%$ CI -0.06 to -0.01 ; $\mathrm{p}=0.014$ ), gastrointestinal (GI) motility agents (slope change $=-0.17 ; 95 \% \mathrm{CI}-0.24$ to $-0.09 ; \mathrm{p}<0.001$ ) and corticosteroids (slope change $=-0.03$; $95 \%$ CI -0.05 to -0.02 ; $\mathrm{p}<0.001$ ), while the slope did not change significantly for analgesics (slope change $=-0.03 ; 95 \% \mathrm{CI}-0.10$ to 0.05 ; $\mathrm{p}=0.510$ ), as there was a decreasing slope for analgesic prepublication (slope estimate $=-0.11 ; 95 \%$ CI -0.17 to $-0.05)$. There was no change in level for any class of medications (table 1).

The time series measured by the proportion of sodiummedication users were consistent with the prescribing rates measured by the number of prescriptions. There was no difference in trends between men and women, although the baseline level for women (73.38 monthly; 95\% CI 70.51 to 76.25$)$ was twofold higher than men (39.10 monthly; 95\% CI 37.61 to 40.59 ). The trends were also largely consistent across age groups. Significant reductions in monthly prescribing postpublication were observed for all age groups, except for patients under 45 years (slope change $=-0.32 ; 95 \% \mathrm{CI}-0.07$ to $0.01 ; \mathrm{p}=0.113$ ) (table 1).

When the ITSA was repeated with 30 months before and after the publication, similar results were obtained (online supplemental table S3).
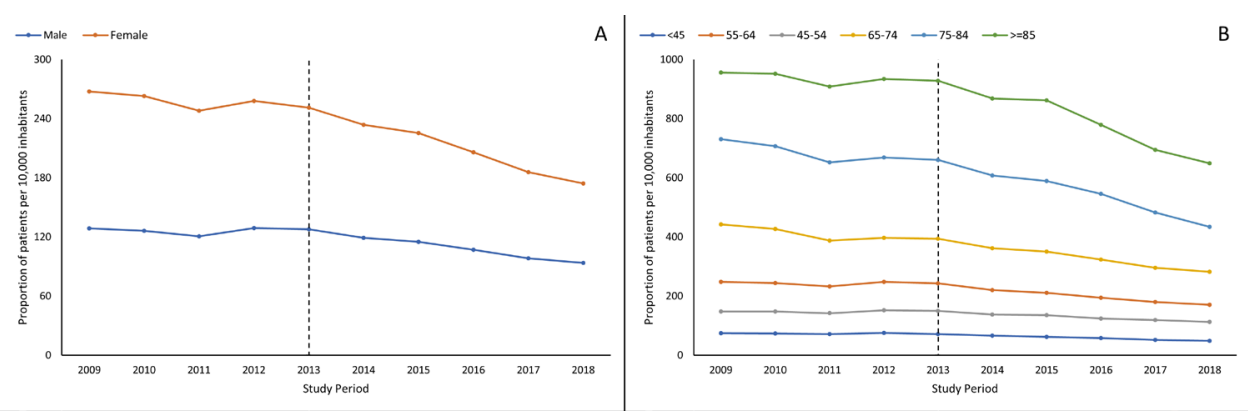

Figure 2 Prescribing trends of sodium-containing medications measured by the proportion of patients from 2009 to 2018 , The Health Improvement Network data; (A) by sex and (B) by age group. 


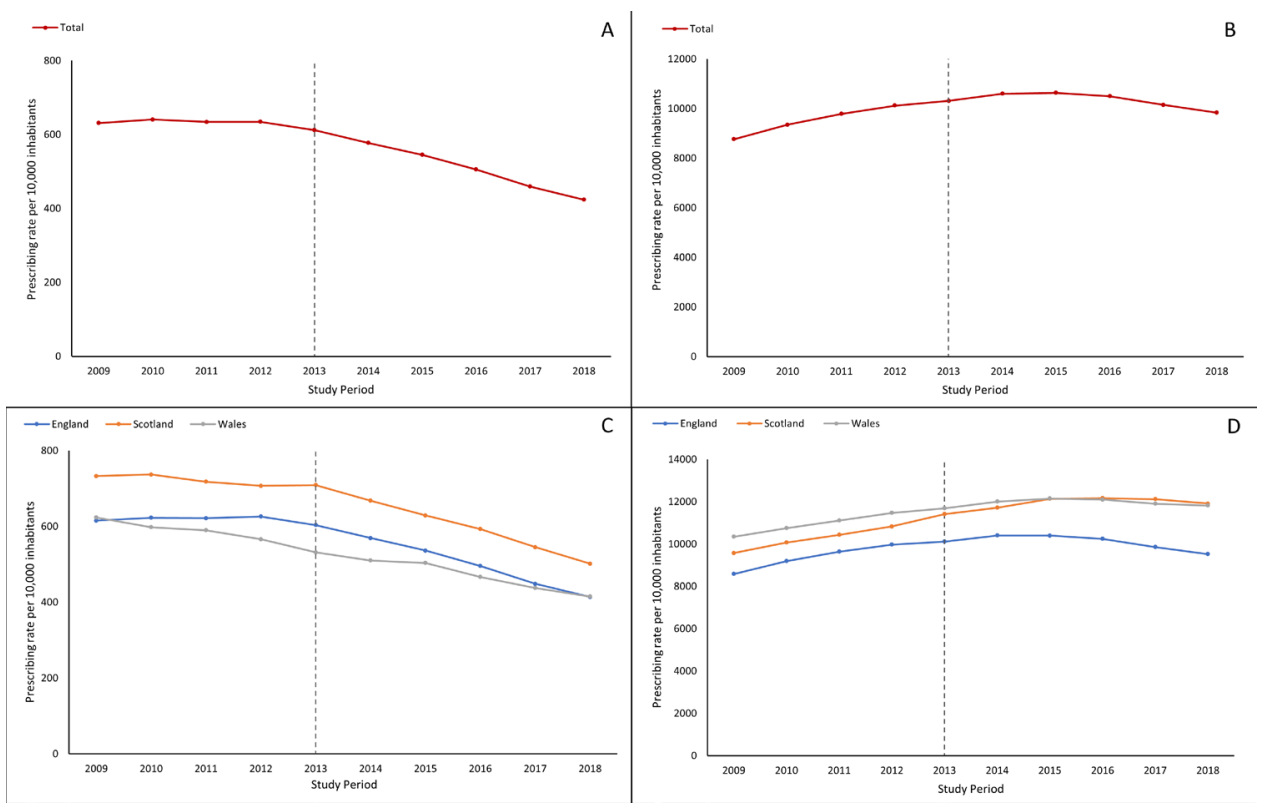

Figure 3 Prescribing trends of sodium-containing medications and control medications from 2009 to 2018, Prescription Cost Analysis data; (A) sodium, prescribing rate; (B) control, prescribing rate; (C) sodium, by regions; and (D) control, by regions.

\section{Changes in prescribing trends after the EMA guideline change in 2015}

To assess the impact of the EMA guideline revision in 2015 on the prescribing of sodium-containing medications, the monthly prescribing from 2014-2015 versus 2016-2017 was compared with ITSA. Significant reductions were observed for both sodium-containing medications (prescribing rate: slope change $=-0.24 ; 95 \% \mathrm{CI}$ -0.41 to $-0.06 ; \mathrm{p}=0.007$; proportion of patients: slope change $=-0.19 ; 95 \%$ CI -0.29 to $-0.08 ; \mathrm{p}=0.001)$ and also for non-sodium control formulations. There was a significant reduction in level when the prescribing of sodiumcontaining medications was measured in the proportion of patients (level change $=-1.78$; $95 \%$ CI -3.35 to -0.21 ; $\mathrm{p}=0.026)$ (online supplemental table $\mathrm{S} 4$ ).

\section{DISCUSSION}

In this study, we showed overall decreasing trends of sodium-containing medication prescribing in the UK after the 2013 BMJ publication highlighting the association of use of these medications with cardiovascular risks. Significant reductions in the trends of sodium-containing medication prescribing were observed after the 2013 BMJ publication. The same change was not observed for the non-sodium-containing control formulations. The results from the THIN database and the PCA database were largely consistent with each other.

The 2013 publication might have had an impact on the prescribing practices of sodium-containing medications in the UK, which was reflected in the observed changes in the trends of prescribing between the prepublication period and the postpublication period. The same change was not observed for non-sodium-containing standard formulations. Comparing the prescribing trends from
2014-2015 to 2016-2017, the guideline revision on excipient labelling by the EMA in 2015 might have induced a further decline in the prescribing of sodium-containing drugs in addition to the impact of the $2013 \mathrm{BMJ}$ publication. Comparing the results from the THIN database and the PCA database, the prescription rates from the THIN data were generally higher than from the PCA data. This observation could be attributed to two methodological differences in data analysis. First, using the patient-level data available in the THIN database, we excluded patients aged under 18 years, who are less likely to receive chronic treatment with the study medications while such information was not available in the PCA database; second, data on GI motility agents were only analysed from the THIN database but not from the PCA database due to unclear product names of certain medicinal products from this drug class in the PCA database.

We found the decreased prescriptions of sodiumcontaining medications were not related to gender, while age might be an influential factor. We found there was a significant change in slope after the publication for patients over 45 years old, most likely due to the high cardiovascular risks in patients over 45 years. ${ }^{15}$ Interestingly, the extent of reduction in prescribing did not simply increase in older age groups. The decline in prescribing slope was the highest in patients aged between 65 and 74 years, with a $0.54 \%$ reduction in monthly prescribing of the sodium-containing medications. The percentage decreases in slope were $0.30 \%$ and $0.19 \%$ in the patients between 75-84 years old and over 85 years old, respectively. As the swallowing impairment increases with old age, more older patients have dysphagia related to other diseases like stroke, Parkinson's disease, dementia or cancer. ${ }^{1617}$ Thus, switching of the effervescent, dispersible 


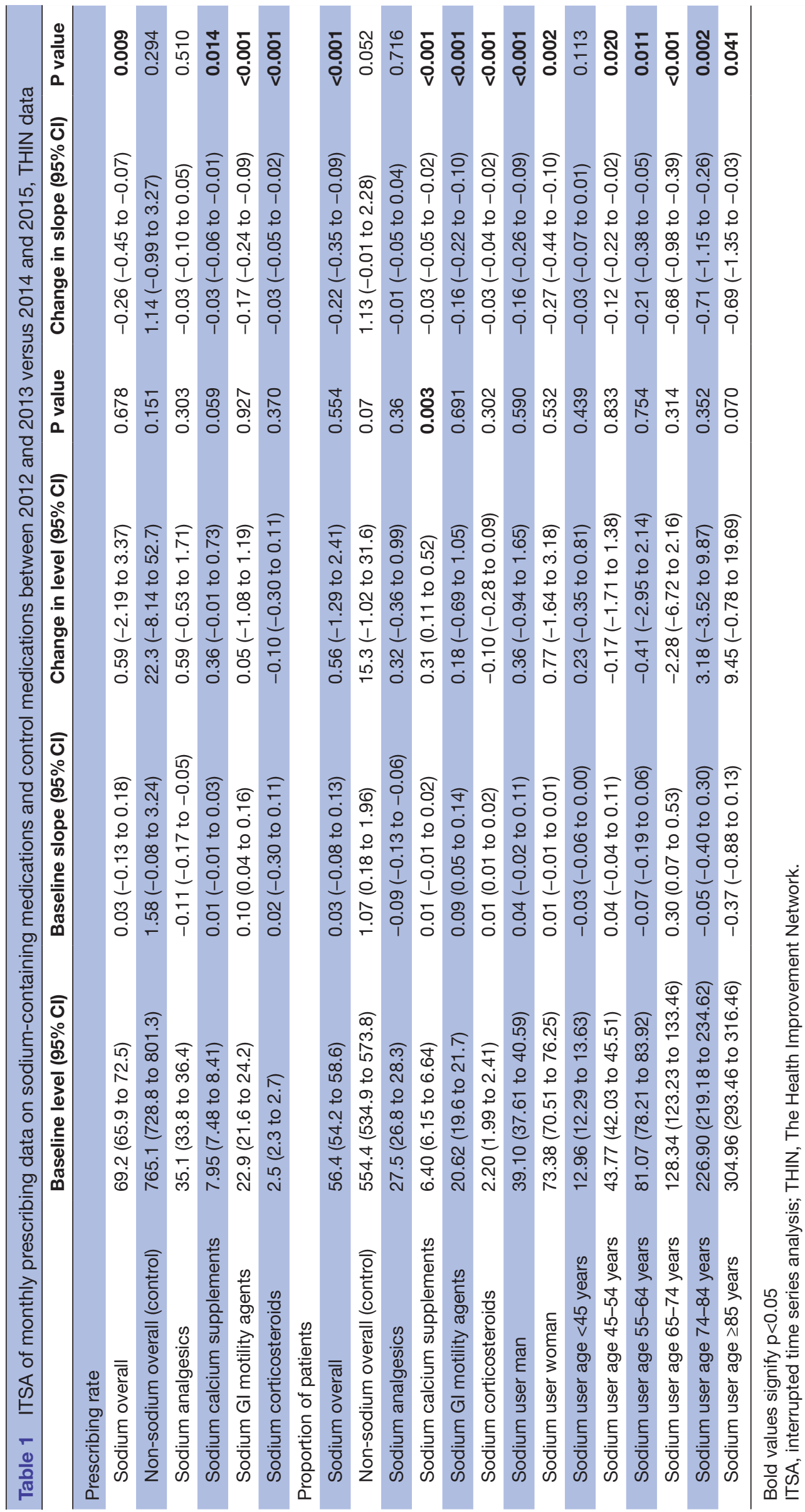


formulations to the non-sodium standard formulations might be less appropriate despite the higher cardiovascular risks.

Across the UK, the prescribing practices in England, Scotland and Wales have changed to different extents, which might be impacted by the 2013 publication. The changes in prescribing trends were significant in England and Scotland, where the trends changed from a plateau before the publication to reduction of $7 \%$ annually after the publication. In Wales, the decreasing trends in sodium-containing medication prescribing pre-existed during the prepublication period and the change in the prescription rate was not significant after the 2013 publication. The driving force for these differential changes in prescribing trends is unclear, especially in absence of change in guidelines. ${ }^{18} 19$ A number of previous studies also reported intraregional differences in the prescribing of various medications. ${ }^{18} 19$ The prescribing rates in Scotland were higher than in England regardless of the publication impact. This could be attributable to differences between NHS prescription charges across regions in the UK, where prescription charges have been abolished in Scotland but not in England. ${ }^{20}$ Therefore, prescriptiononly medications are preferable compared with over-thecounter medications for patients in Scotland due to lower personal cost, especially when the medications are used long term. ${ }^{21}$ Notably, the prescription rate was the lowest in Wales despite the free prescriptions in this region. ${ }^{20}$ The lower prescription rates could be due to the relatively lower chronic disease burden in this region. ${ }^{22}$ The relatively low prescribing rates of other drugs in Wales than in England have been reported by previous studies. ${ }^{23}$ In addition, national prescribing indicators were set in Wales to promote rational prescribing in certain clinical areas. ${ }^{24}$ One of the aims of the national prescribing indicators published over the study period was to reduce the prescribing of non-steroidal anti-inflammatory drugs, which are the major component of sodium-containing drugs. $^{24}$

The prescribing trends for medications of different therapeutic classes varied during the prepublication and postpublication periods. Analgesics were the most commonly prescribed sodium-containing medications while the prescribing was not changed after the publication. The prescribing rate of analgesics started to decrease during the prepublication period as initial concerns regarding associations with higher blood pressure of effervescent paracetamol tablets emerged in 2006 and were echoed in 2008 and 2009. ${ }^{25-27}$ Some practitioners might therefore have adopted a more cautious attitude towards prescribing effervescent paracetamol earlier than to other sodium-containing formulations. The 2013 publication confirmed the association with cardiovascular adverse events of the medications. Calcium supplements and oral corticosteroids are the other two major classes of sodium-containing medications that may have been affected by the publication. The prescribing of both medication classes declined significantly since the publication.
Apart from the impact from the BMJ publication, the changes in trends were possibly associated with other evidence updates over the study period. For example, the meta-analyses in 2012 and 2014 confirmed that calcium was not effective for the prevention of bone fractures, ${ }^{28} 29$ which could have led to the overall reduction in calcium supplement prescribing. Two studies also reported a declining trend in prevalence of oral corticosteroid use in the UK and France from 2013 to $2014 .{ }^{30}{ }^{31}$ Therefore, the observed trend changes could be the summation of the effects from the publication and other evidence changes over the study period.

\section{Strengths and limitations}

To the best of our knowledge, this is the first study evaluating recent trends for the prescribing of medications of sodium-containing, dispersible, effervescent or soluble formulations. Our analyses involved both the aggregatelevel data for whole nations and the patient-level data from the THIN database, and we have shown the consistency in results when measured in different parameters and from different databases. We have been able to assess the impacts of the 2013 BMJ publication on different regions in the UK, on medications from different therapeutic classes and different patient demographic groups.

However, there are limitations to our study. Our data sources were limited to the prescribing information in primary care and we were unable to evaluate the impact of the publication on prescribing practice in secondary care. Although we conducted the analysis on patientlevel data, certain clinical characteristics of the patients, such as comorbidities and exposure time of the sodiumcontaining medications, were not included. We were not able to explore the factors other than age and sex, which might be associated with medication prescription or discontinuation as suggested by other previous publications. ${ }^{9}{ }^{10}$ Furthermore, we were not able to include all dispersible, effervescent or soluble formulations available on prescription. As we aimed to investigate the impact of the publication, we included all equivalent formulations to the drugs included in the original publication. ${ }^{3}$ Although we used the pseudo-randomised ITSA with a control series included, we were still not able to establish the causal relationship between the intervention and the observed changes, the effect of other interventions or evidence changes during the analysis time period cannot be ruled out. We have conducted a number of multiple repeated analyses on different patient groups and medication classes, which could potentially introduce multiplicity issues with inflated statistical error rates. Results from the stratified statistical tests should be interpreted with caution.

\section{CONCLUSION}

In conclusion, the prescribing trend of sodiumcontaining, dispersible, effervescent or soluble medications has reduced significantly after the BMJ publication 
in 2013 highlighting associations between high sodiumcontaining medications and cardiovascular risks. The reduction was significant in patients aged over 45 years old. Across different regions in the UK, England and Scotland were affected by the publication the most. Changes in the prescribing trends for medications of different therapeutic classes were observed with variations, possibly due to other evidence changes during the study period. Further studies are warranted to investigate the factors that may drive the discontinuation/switching of the medications and the long-term health effects associated with medication discontinuation or switching.

\section{Twitter Chengsheng Ju @ChengshengJ and Li Wei @LiWeiUCL}

Contributors CJ conducted the data analysis, interpreted the data and wrote the original draft under the supervision of LW and JG. LW and JG conceptualised the study, interpreted the data and critically reviewed and commented on all drafts. IM and TMM interpreted the data and critically reviewed and commented on all drafts.

Funding This study was supported by an internal research grant (reference: CRT-36619).

Competing interests None declared.

Patient consent for publication Not required.

Ethics approval Ethical approval was obtained from THIN Scientific Review Committee (SRC), protocol reference number: 20SRC004.

Provenance and peer review Not commissioned; externally peer reviewed.

Data availability statement № additional data available.

Supplemental material This content has been supplied by the author(s). It has not been vetted by BMJ Publishing Group Limited (BMJ) and may not have been peer-reviewed. Any opinions or recommendations discussed are solely those of the author(s) and are not endorsed by BMJ. BMJ disclaims all liability and responsibility arising from any reliance placed on the content. Where the content includes any translated material, BMJ does not warrant the accuracy and reliability of the translations (including but not limited to local regulations, clinical guidelines, terminology, drug names and drug dosages), and is not responsible for any error and/or omissions arising from translation and adaptation or otherwise.

Open access This is an open access article distributed in accordance with the Creative Commons Attribution Non Commercial (CC BY-NC 4.0) license, which permits others to distribute, remix, adapt, build upon this work non-commercially, and license their derivative works on different terms, provided the original work is properly cited, appropriate credit is given, any changes made indicated, and the use is non-commercial. See: http://creativecommons.org/licenses/by-nc/4.0/.

\section{ORCID iDs}

Chengsheng Ju http://orcid.org/0000-0001-7860-6262

Li Wei http://orcid.org/0000-0001-8840-7267

Isla S Mackenzie http://orcid.org/0000-0002-3680-7127

Thomas M MacDonald http://orcid.org/0000-0001-5189-6669

Jacob George http://orcid.org/0000-0001-8154-8278

\section{REFERENCES}

1 Frieden TR, Berwick DM. The "Million Hearts" initiative-preventing heart attacks and strokes. N Engl J Med 2011;365:e27.

2 Whelton PK, Appel LJ, Sacco RL, et al. Sodium, blood pressure, and cardiovascular disease: further evidence supporting the American Heart Association sodium reduction recommendations. Circulation 2012;126:2880-9.

3 Mozaffarian D, Fahimi S, Singh GM, et al. Global sodium consumption and death from cardiovascular causes. N Engl J Med 2014;371:624-34.

4 Eaton L. Food agency launches campaign to reduce salt intake. BMJ 2004;329:644.2.

5 Bibbins-Domingo K, Chertow GM, Coxson PG, et al. Projected effect of dietary salt reductions on future cardiovascular disease. $N$ Engl J Med 2010;362:590-9.
6 Barton P, Andronis L, Briggs A, et al. Effectiveness and cost effectiveness of cardiovascular disease prevention in whole populations: modelling study. BMJ 2011;343:d4044.

7 George J, Majeed W, Mackenzie IS, et al. Association between cardiovascular events and sodium-containing effervescent, dispersible, and soluble drugs: nested case-control study. BMJ 2013;347:f6954.

8 Benitez-Camps M, Morros Padrós R, Pera-Pujadas H, et al. Effect of effervescent paracetamol on blood pressure: a crossover randomized clinical trial. J Hypertens 2018;36:1656-62.

9 Perrin G, Korb-Savoldelli V, Karras A, et al. Cardiovascular risk associated with high sodium-containing drugs: a systematic review. PLoS One 2017;12:e0180634.

10 Perrin G, Berdot S, Thomas F, et al. Evaluation of exposure to effervescent drugs in a large health check-up population in France: a cross-sectional study. BMJ Open 2018;8:e022368.

11 Lewis JD, Schinnar R, Bilker WB, et al. Validation studies of the health improvement network (THIN) database for pharmacoepidemiology research. Pharmacoepidemiol Drug Saf 2007;16:393-401.

12 Blak BT, Thompson M, Dattani H, et al. Generalisability of The Health Improvement Network (THIN) database: demographics, chronic disease prevalence and mortality rates. Inform Prim Care 2011;19:251-5.

13 Davies JE, Taylor DG. Individualisation or standardisation: trends in National Health Service prescription durations in England 1998-2009. Prim Health Care Res Dev 2013:14:164-74.

14 Naser AY, Wang Q, Wong LYL, et al. Hospital admissions due to dysglycaemia and prescriptions of antidiabetic medications in England and Wales: an ecological study. Diabetes Ther 2018;9:153-63.

15 Nedeltchev K, der Maur TA, Georgiadis D, et al. Ischaemic stroke in young adults: predictors of outcome and recurrence. J Neurol Neurosurg Psychiatry 2005;76:191-5.

16 Schiele JT, Quinzler R, Klimm H-D, et al. Difficulties swallowing solid oral dosage forms in a general practice population: prevalence, causes, and relationship to dosage forms. Eur J Clin Pharmacol 2013;69:937-48.

17 Ney DM, Weiss JM, Kind AJH, et al. Senescent swallowing: impact, strategies, and interventions. Nutr Clin Pract 2009;24:395-413.

18 Bateman DN, Good AM, Afshari R, et al. Effects of licence change on prescribing and poisons enquiries for antipsychotic agents in England and Scotland. Br J Clin Pharmacol 2003;55:596-603.

19 Chan JP, Boyd G, Quinn PA, et al. Emollient prescribing formularies in England and Wales: a cross-sectional study. BMJ Open 2018;8:e022009.

20 NHS prescription charges. Drug Ther Bull 2015;53:45-8.

21 Groves S, Cohen D, Alam MF, et al. Abolition of prescription charges in Wales: the impact on medicines use in those who used to pay. Int $J$ Pharm Pract 2010;18:332-40.

22 Steel N, Ford JA, Newton JN, et al. Changes in health in the countries of the UK and 150 English local authority areas 1990-2016: a systematic analysis for the global burden of disease study 2016 . Lancet 2018;392:1647-61.

23 Wan M, Horsfall LJ, Basatemur E, et al. Vitamin D prescribing in children in UK primary care practices: a population-based cohort study. BMJ Open 2019;9:e031870.

24 Group AWMS. National prescribing indicators. Available: http://www. awmsg.org/medman_cepp.html [Accessed 20 Jul 2020].

25 Douglas L, Akil M. Sodium in soluble paracetamol may be linked to raised blood pressure. BMJ 2006;332:1133

26 Jarrett DRJ. Paracetamol and hypertension: time to label sodium in drug treatments? BMJ 2008;336:1324.

27 Ubeda A, Llopico J, Sanchez MT. Blood pressure reduction in hypertensive patients after withdrawal of effervescent medication. Pharmacoepidemiol Drug Saf 2009;18:417-9.

28 Murad MH, Drake MT, Mullan RJ, et al. Clinical review. Comparative effectiveness of drug treatments to prevent fragility fractures: a systematic review and network meta-analysis. J Clin Endocrinol Metab 2012;97:1871-80.

29 Reid IR, Bolland MJ. Calcium risk-benefit updated--new WHI analyses. Maturitas 2014;77:1-3.

30 Bénard-Laribière $A$, Pariente $A$, Pambrun $E$, et al. Prevalence and prescription patterns of oral glucocorticoids in adults: a retrospective cross-sectional and cohort analysis in France. BMJ Open 2017;7:e015905

31 Chalitsios CV, Shaw DE, McKeever TM. A retrospective database study of oral corticosteroid and bisphosphonate prescribing patterns in England. NPJ Prim Care Respir Med 2020;30:5. 